Journal of Humanities and Social Sciences Studies (JHSSS)

ISSN: 2663-7197

DOI: $10.32996 /$ jhsss

Journal homepage: https://al-kindipublisher.com/index.php/jhsss

\title{
Financial Literacy in Millennials
}

Latika Murarka*1 and Dr. Karen Kashmanian Oates ${ }^{2}$

${ }^{1}$ Jesus and Mary College, Delhi University

${ }^{2}$ Professor Biology and Biotechnology, Worcester Polytechnic Institute, USA

Corresponding Author: Latika Murarka, E-mail: latikamurarka1@gmail.com

ARTICLE INFORMATION

Received: October 01, 2020

Accepted: November 22, 2020

Volume: 2

Issue: 6

DOI: 10.32996/jhsss.2020.2.6.5 KEYWORDS

Financial Literacy, Financial Literacy in teenagers, Personal Finance, Finance management for teenagers, budgeting decisions for teens

\section{ABSTRACT}

The main goals for this project include are to find out the current knowledge of teens (14-20) with regard to financial literacy, to create a survey from which external information can be gathered and to analyze the results and observations of this survey, and thus make recommendations to financial and educational institutions. The goal of teaching financial literacy to teens is to reach them with relevant information they can really use in life now and in the future. This can be extended to financial decision making later as they enter adulthood. It's useful to center instruction around important upcoming life events such as college decisions, budgeting on a tight budget, use of credit and debit cards and learning how to save and invest in the future. This also includes managing personal finance in college, especially if they decide to go to a foreign country. In this research project we will investigate the knowledge base teenagers have regarding money management and decision making. As a base we will use one of the largest financial services surveys for financial literacy created by the National Financial Educators Council. The goal of this project is to create a list of 30 questions derived from the most appropriate national surveys and administer it to more than 50 individuals, ages $14-20$. The key insights included that $71.2 \%$ respondents did not consider themselves financially literate. It was clearly visible that respondents lacked knowledge on topics such as inflation, credit score and insurance. Moreover, $78.8 \%$ of respondents have not taken any class/course in financial literacy. The report concludes with recommendations to both financial institutions and educational institutions to increase specific areas of financial literacy.

\section{Introduction}

Financial literacy, throughout the years, may focus on different skills depending upon the stage of life and one's economic status. This research project looks at the financial literacy of young adults in India.

According to the Organization for Economic Co-operation and Development (OECD), financial literacy is - "a combination of awareness, knowledge, skill, attitude and behavior necessary to make sound financial decisions and ultimately achieve individual financial wellbeing." (Organization for Economic Cooperation and Development, 2011)

\subsection{Importance of Financial Literacy}

Most teenagers are dependent on their parents for many things, including their finances. However, as soon as they start living independently, they will be forced to look into their finances all by themselves. Independence calls for an urgent need to be financially literate in order to make financially secure life decisions.

K C AL-KINDI CENTER $\mathbf{R}$ DFOR RESEARCH AND $\mathbf{R} \mathbf{D}$ DEVELOPMENT Your gateway to world-class research
Published by Al-Kindi Center for Research and Development. Copyright (c) the author(s). This is an open access article under CC BY license (https://creativecommons.org/licenses/by/4.0/) 
Unlike other subjects taught in high school, the skills and knowledge associated with financial literacy are rarely discussed, nor are they a part of the curriculum. If such information regarding financial literacy is taught, students can develop a more positive attitude towards money management. Money is something teenagers are going to manage all their life, and plays a vital role in their future. Hence, they can take financially informed decisions by understanding the basics before making any financial commitments.

The main aim of this research is to discover how much teenagers know about managing money and to provide recommendations to education and financial institutions in order to ensure that students know and use financial literacy in their day to day lives. In the case of credit cards and debit cards, they are being used widely as the world is moving towards a cashless economy. In this scenario, it is extremely important that the target age group of this study knows the mechanisms of using cards and managing card statements. Similarly, one of the most important decisions teens face is regarding college. It must be noted that while taking such a decision, they should be aware of the cost, and consider the return on this investment they are going to make. All these factors highlight the need for financial literacy at a young age.

\subsection{Money Management as a National Skill}

The concept of money management can be extended to savings. It is important that teens understand the need for savings now, so that they have the knowledge to save for the future. It is also seen that a lot of teenagers do have saving accounts made in their name by their parents, but they have no knowledge on how to operate them. Schemes such as student loans, and saving accounts for minors is not something they should shy away from, however must know the details and cautions of. Basic functions such as writing a check, calculating interest and maintaining bank accounts is something every teenager in India should know how to do.

Social media has become a dominant force in the lives of teens. It provides helpful financial applications, yet there is no certain guarantee that these are legitimate. All information posted there may not be true and hence extreme caution should be taken while examining this data. (Monica Jasuja, 2017, February 26) Teenagers should know the difference between right and wrong in order to stay safe from traps laid by fraudulent applications, which furthermore proves the point that financial literacy, including digital financial literacy, is a mandatory requirement in today's world.

As our nation increases in financial complexity, many teenagers may not have parents who have lived in our current environment or with a tradition of financial literacy. Hence, they do not get the opportunity to learn from financially literate families. Since they are the future of our country, it is vital that they learn money management at a young age. An important role is played by parents here. Parents must take some initiative since they form the basis for financial literacy in children. Teenagers often look up to the way their parents manage finances and adapt similar methods used by them. They learn from their parents' experiences, both good and bad. Since this subject matter is crucial, it should also be imparted to them in a formal environment, where they are guided in a proper manner.

Many financial institutions such as the Reserve Bank of India (RBI) and National Institute of Securities Market (NISM) have highlighted the need for financial literacy and introduced a number of programs on the same for high schoolers (Reserve Bank of India, n.d, A \& National Institute of Securities Markets, 2014, A). These programs aim to deliver knowledge on financial literacy ranging from the basics to advance in order to get a better understanding. However, they are not very widely adapted.

This research paper explores the importance of financial literacy in the age group of 14-20 year old students. The focus in on achieving certain targets which will help teens evolve into financially literate individuals, which include -

- To find out the current knowledge set of teenagers (14-20) with regard to financial literacy

- To create a survey from which external information can be gathered, and

- To analyze the results and observations of this survey, and thus make recommendations to financial and educational institutions

To be educated means to not only have mastered the required school subjects but to have the skills necessary for a productive and financially secure life. This financial knowledge is beneficial to each and every individual and will broaden their horizon on financial literacy. If started at a young age, a child can gain a lot more knowledge and save themselves from the burdens of managing huge debts. The education on management of money and an individual's financial literacy, will not be wasted and is something individuals will use throughout their lives. Wherever or whoever a person may be, financial literacy remains the only constant. 


\section{Literature Review}

This chapter highlights the problem of lack of financial literacy among teenagers aged 14-20 in India. We begin by giving an overview of the problem, followed by a thorough analysis of what information we have.

\subsection{Introduction}

Money is an integral part of today's world and efficiently managing this money is an art. When this basic component is ignored and not taught to students, they often grow up to be confused and unsure about many financial decisions, which leads to mishandling of money. These young adults then fail to indulge in financial markets and institutions, and take ages to learn the proper way to use money. If this lesson is taught at an earlier age, a lot of problems that teens face now and would face in the future could be reduced.

A common example of insufficient financial knowledge would be a teenager who incurs all their expenditures on the credit card, without realizing if they even have the required funds to pay for them. When unable to meet this expense, an interest is charged increasing this debt even further. No student would want to lead a life where they are constantly struggling to pay off their debts or loans. Looking at every minute detail in documents and understanding the outcome of all financial decisions is an important part of financial literacy.

A person usually understands the value of money when they earn it through their own hard work. Under the umbrella of their parents, teens tend to take money for granted. They are getting a regular supply of cash now but soon when they live an independent lifestyle, they will have to fend for themselves. Financial literacy gives them the power to get through this transition from dependence to independence at ease.

\subsection{National Organizations Working for Financial Literacy}

There are a number of organizations that have realized the importance of financial literacy specially in teenagers. One of the biggest of these is National Financial Educators Council (NFEC) that provides resources, training and expertise in financial literacy, which it considers a critical life skill. They have taken out many surveys and tests such as National Financial Capability Test, Financial Foundation Decision Test, Student Loan test and more, which are all available online. (National Financial Educators Council, n.d)

Seeing the need of the hour, Reserve Bank of India (RBI) came up with a financial literacy program in order to create awareness regarding financial literacy. It targets a number of age groups including children, for which attractive booklets are made available on the website in 13 different languages across India. Some topics are also explained through short stories. It elaborates on basic concepts such as needs, wants, banking, investment and others through illustrations and text. There are also short explanatory videos available online at their forum. Moreover, they came up with the concept of a Financial literacy week which was observed from February 10-14 this year. (Reserve Bank of India, 2007, B)

Further benefiting the public, RBI has encouraged Financial Literacy Centers (FLCs) to come up with audiovisuals on financial literacy in order to make it easier to comprehend it. These audiovisuals cover topics such as "Basic Financial Literacy", "Going Digital" and "Unified Payments Interface". They are available in different languages to increase audience reach. (Reserve Bank of India, n.d, C)

To make matters more interesting, the Insurance Regulatory and Development Authority (IRDAI) started making comic strips to make the subject of financial literacy more appealing. Through these strips, they aim to teach simple financial terms in a story form. (Insurance Regulatory and Development Authority of India, n.d).

The National Centre for Financial Education (NCFE) is a company solely for the purpose of promoting financial literacy. They introduced two programs, particularly for students, including Money Smart School Program (MSSP) for grade $6^{\text {th }}-10^{\text {th }}$ students, and Financial Awareness and Money Training (FACT) for under graduate and post graduate students. The former aims to voluntarily involve financial literacy as a part of the school curriculum and the latter ensures that students know all basics before joining the workforce. (National Centre for Financial Education, 2015)

In 2013, NCFE formulated an exam called the National Financial Literacy Aptitude Test (NFLAT) which aimed at testing the financial literacy of students of class $6^{\text {th }}$ to $12^{\text {th }}$. There was huge participation for the same and this test became a yearly examination where pupils from different schools across India participated. (National Institute of Securities Markets, 2014, B) However, the results of the first test were quite unsatisfactory following which, the National Institute of Securities Market (NISM) came up with an initiative known as Pocket Money Program. This program was to improve financial literacy among youngsters so as to ensure better decision making on their part and living a financially sound life. The target group was 
students of class 8th to 12th, where they were taught topics like money management, investments, borrowings, banking and others.

\subsection{National Surveys}

Surveys help in getting a good estimate of the current knowledge people have. By taking an unbiased sample from the population, we can understand what information is lacking in the subject and hence provide scope for improvement. It is a good way of verifying whether the current schemes and programs on financial literacy are actually beneficial.

The following describes several national surveys where we can get a good look of where our nation currently stands with respect to financial literacy in teenagers.

\subsubsection{Survey conducted by Visa (Feb-April 2012)}

A survey was conducted by Visa, a financial services company, where 25,500 people were interviewed across 28 countries including India. Only $35 \%$ of the Indian respondents were termed financially literate. Additionally, the area where India lacked the most was "talking to your children ages 5-17 about money management issues" with a score only 19.6 out of 100. India was ranked $23^{\text {rd }}$, which highlights the need for financial literacy. (Kaushambi, 2017, June 15)

\subsubsection{Survey conducted by IIM and Citi (June 2012)}

The Indian Institute of Management Ahmedabad conducted a survey with the help of Citi Foundation to find out the level of financial literacy in India among different age groups. According to the findings, only about 22\% of the students (aged 17-22) have high financial knowledge and more than $50 \%$ score only a very low mark. The main topics where students underperformed were compound interest, time value of money and inflation. (Agarwalla et al., June 2012)

\subsubsection{Standard \& Poor's Financial Services LLC (2014)}

According to a survey taken by S\&P, where questions were asked around risk diversification, inflation, interest and compound interest, only $24 \%$ of the Indian population turned out to be financially literate. The rest $76 \%$, have a basic level knowledge or are very poor in financial literacy. A key finding from this survey was that with an increase in the level of education, more people became financially literate. This was confirmed as only $18 \%$ adults with primary education are financially literate, while $30 \%$ and $38 \%$ of adults with secondary and tertiary level of education respectively are financially literate (Meera Santoshi, 2016, May 25).

\subsection{Young Adults \& Financial Knowledge}

Financial decisions comprise of an important part of a young adult's life. They often have to make small decisions and face a number of trade-offs due to their limited finances. They should know the importance of choosing needs before wants, savings over loans, uses of credit cards, informed investing and other such decisions. At some point in their life, the use of financial knowledge will be unavoidable. Managing funds in college, and soon afterwards in the outside world is not easy, and will definitely require financial education and experience.

Basic decisions like food budgeting, travelling expenses and other essential ones are a huge part of managing money that teens have to face daily. The question that arises here is whether they will be able to do it independently. Some examples of these include, whenever a student wants to buy a book online, they should know the exact procedure to follow without running to their parents and asking for help. When the credit card statements arrive, they should be able to comprehend and pay for them all by themselves. In light of this, creating a financial literacy program is an opportunity to educate teenagers in making money management decisions they face now and in the future.

Savings plays an important role in financial literacy, and is a concept which proves to be extremely advantageous. Regularly saving a small percent of your pocket money can lead to a huge amount being saved up for the future, which can be used for college as well as other expenses. The benefits of savings are endless (Jeremy Biberdorf, 2015, March 18 \& Jaimie Kemper, 2013, March 26). It provides security and acts as a savior in cases of emergencies. A good way to imbibe the skill of saving is for parents to open savings account for minors (age 10 - 18), so they can not only manage money but also be acquainted to the basic facilities offered by the bank which will help them in the future. These accounts later automatically get converted to normal savings accounts once the child becomes 18 .

Financial literacy is a broad concept. It lays down a number of principles to follow which will help in better money management. These range from organizing finances to understanding risk and return. One of the most vital principles of managing money is to spend less than you earn. Planning becomes the next key component as it will outline how a teenager will allocate budgets and use their money wisely. Surplus funds can always be invested in order to earn more money through 
the concept of interest rate. By comprehending the meaning behind these principles, more teenagers can practice being money smart which will help them in their future.

\subsection{Curriculum Development for Schools in Financial Literacy}

A number of initiatives have been taken for promoting financial literacy among teens in India. Yet, there is not any effort to make it a mandatory subject to be learnt by all students in schools. Learnings are usually imbibed in children right from young age and financial learnings should be no exception to that. There is a growing need for spreading financial awareness and knowledge, and the first step towards this is to introduce financial literacy in schools.

A child starts developing knowledge about finance through the concept of piggy banks. They often get excited whenever they find an extra rupee to put inside these piggy banks. These highlight savings and how after a long period of time, even putting small amounts of cash can lead to a good sum being saved. The aim here is to take these learnings further, and teach kids, the other aspects of finance as well, so that by the time they manage their own household, all required financial knowledge is already known to them.

When the subject of financial literacy will be taught to students in a formal atmosphere, they will pay more attention to it. Adding monthly assignments and tests can further motivate them to learn the core of the subject. Finance is known to be a complicated and rather difficult area. If this subject matter is imparted in interesting ways, it will catch the attention of students. For example, a quite famous rule in finance is the rule of 72 . It says, in order to find out how many years it's going to take to double your initial investment of money, subject to a compound interest every year, you simply have to divide the principal amount by 72 and there goes the answer. Such techniques increase the engagement of students and makes the matter more appealing to them.

Our current generation comprises of our future financial decision makers. In order to run a nation with financially smart people, which also increases economic productivity, it is essential to provide the basic knowledge to students. It is often seen that if people are unaware about the various financial instruments and their uses, they will fail to reap the benefits of them. For example, a financially illiterate person would usually be apprehensive of making investments while another one would be unable to understand how to get insurance. The way to avoid such circumstances is to introduce financial literacy in the curriculum and ensure every student passes the basic financial literacy test.

This program will be even more suitable for high schoolers, who can not only learn the subject, but also apply it in their everyday lives. Drawing money from banks, using credit cards, earning stipends at internships or salary at part time jobs, all can be done in a more efficient manner by understanding money management. Getting practical experience while learning the subject complements each other and leads to a success in both areas. Hence, introducing financial literacy in the curriculum will be a much-needed start to making the world more financially educated.

It doesn't matter what stream a person chooses in their life, whether they are teachers, doctors, artists, or chefs, one thing that remains common throughout one's life is managing their own funds. And this financial education, given at a young age to all, can be extremely beneficial in setting a solid foundation for a financially secure life.

\section{Methodology}

The following Methodology section represents the methods used in forming this research paper and accomplishing the three goals of this project.

\subsection{Current Knowledge of Teenagers Regarding Financial Literacy}

Understanding the current knowledge of teenagers on financial literacy forms the basis of this research project. The major portion of the research was done through secondary research, where most data sources were found with the help of the internet search engines. As a means to get an understanding of the current knowledge, numerous articles, blogs, papers, surveys, programs were reviewed. These included papers solely based on financial literacy in teenagers and in general.

Different key words and phrases were entered into the internet search engine such as "financial literacy in teens, financial literacy in India, programs to promote financial literacy in India, Importance of financial education, principles/components of financial literacy" and others, to develop a list of resources and references. After diving deep into various sources, and conceptualizing data from all over the world, a series of questions for the survey were developed based on this background research that was both relevant and timely for the age group chosen. 


\subsection{Creation of the Financial Literacy Survey}

After conducting secondary research, the next step was to review primary research surveys focused on financial literacy in teenagers. Utilizing the key take-aways from these surveys and other national surveys, a survey was created, comprising an important part of this original research project. This survey was meant for the participation of a minimum of 30 teenagers within the age category of 14-20-year-old teenagers in India.

The design of this survey was to test the different areas of financial knowledge in teens, including their financial behavior, attitude and basic knowledge on topics such as compound interest, insurance, debt etc. At the same time, it was important to keep in mind to set the level of the questions according to the age group. The desired outcome was to understand the areas where participants lack financial knowledge, and hence where financial education would be best focused.

After a thorough understanding of a number of financial literacy surveys led by international organizations such as OECD, NFEC and others, a start to a potential questionnaire was found. Questions from these surveys were borrowed, but were tailored according to the target audience. This was an important step since the survey dealt with teenagers who had a very basic knowledge and experience in finance. A few original questions were also included in this survey, inspired from the others, in order to cover all aspects of financial literacy and get a proper understanding of how the financial minds of teenagers' work. A total of 27 questions were finalized, either multiple choice or rating based questions.

\subsection{Survey Platforms}

There are a variety of survey platforms available on the internet. Although they broadly offer the same features, they do have little differences such as the package, limit on the number of questions and others. In the end, three platforms were shortlisted - google forms, survey monkey and word press forms. I decided to go with google forms as I have had past experience with this tool and it gave a promising result. Moreover, it was completely free and offered a vast number of features. To make the survey more aesthetically pleasing, a colored background and a banner image were added.

A few test runs showed that the survey took approximately 5-7 minutes for an average person. This short time span was intended to make this survey as engaging and interesting as possible, so that maximum responses could be achieved.

\subsection{The Survey}

The survey was formed in a way so that different aspects of financial literacy could get covered. It started out with general finance questions, went on to test the financial behavior and attitude of teens and concluded with a test on a few basic finance concepts. The demographic details such as age, gender and parents' qualification were added towards the end of the survey. This survey, containing all the information, can be viewed in the Appendix I below. A sample of the questions is as follows:

\section{Q. Have you heard of the term financial literacy?}

- Yes

- No

- Maybe

Q. Are you involved in the financial decisions of your household?

- Yes

- No

- A little

Q. Have you taken any class/course which has helped you in managing your money?

- Yes

- No

Q. Would you consider taking such a class on financial literacy?

- Yes

- No

- Maybe

Q. Do you own a bank account?

- Yes

- No 
- Yes, but I don't operate it

Q. How financially literate do you think you are?

Define FL: a combination of awareness, knowledge, skill, attitude and behavior necessary to make sound financial decisions and ultimately achieve individual financial wellbeing.

Q. How important is it to keep financial records/bills of where you spend your money?

Q. I feel capable of handling my financial future

Q. I read all financial documents before I sign

Q. Which of the following financial products can help you lower your personal risk?

- Insurance

- Mutual funds

- Retirement plans

- None of the above

Q. If the current inflation rate is at $3 \% \ldots$

- Investments in securities (stock market, mutual funds) adjust to market conditions by $3 \%$.

- My net income needs to increase by 3\% to maintain my current lifestyle.

- My savings need to increase by $3 \%$ to maintain my current lifestyle.

- Uncertain

Q. Suppose you put ₹100 into a savings account with a guaranteed interest rate of $2 \%$ per year. how much would be in the account at the end of five years?

More than

- $\quad ₹ 110$

- $\quad$ Exactly ₹110

- Less than ₹110

- Or is it impossible to tell from the information given

- Don't know

\subsection{Method of Data Analysis}

A total of 90 respondents of the Indian student population responded to the survey. After compiling all the data, it was analyzed using Google forms. Google forms was chosen for the survey because it had analytical tools which could help catalog the data and organize it in a comprehendible way by converting it to an excel sheet. The analytical tool has the capacity to build a number of graphs, pie charts and tables. Microsoft Excel itself had a number of features to categorize the data and make conclusions.

It was important to look at this data from different perspectives, such as sorting it out by age, gender and parental qualifications. This also formed a strong basis for comparison. By trying out different permutations and combinations, quite interesting conclusions could be made. This formed a part of deriving results after analyzing the data. A separate result for each question or a combination of questions was found and compiled. The findings tapped on different aspects of financial literacy due to the diversity of the questionnaire. All the original data of the responses and analysis can be found in the Appendix II of this research paper.

\subsection{Dissemination of Results Using an Infographic}

In order to disseminate the data in a meaningful and attractive manner, an infographic was used. This not only highlighted the crucial findings, but would also increase the engagement of readers. A number of platforms were available for this with different features and templates such as Canva, HubSpot, Venngage, Visme and Piktochart. Out of all these, Canva was chosen as it offered the most aesthetic values and was considered a good fit for the data. 
The infographic consists of a mixture of information from the background as well as the results section. All useful and unique data is added to it, along with figures, graphs, clipart and pictures. This infographic gives a gist of the research paper, while emphasizing on important aspects of financial literacy. The major focus is given to conveying the primary results of the financial literacy survey and what it says about the current level of financial knowledge in youth.

\section{Results}

In this chapter, the key results found through the survey will be highlighted. It gives an insight into where the current generation stands on financial literacy, and what they know.

\subsection{Survey Findings}

The financial literacy survey was sent out for 15 days. In this time span, a total of 90 responses were attained. Upon analysis, it was found that 60 females and 30 males had taken the survey. The age group was divided among 14 to 20-year-old students. Two categories were made for comparison, 14-16-year-old students and 19-20 year old students. In the former category, there were 23 responses and for the latter there were 37 responses. The parents of the respondents had different educational qualifications, with 4 of them having no high school degree, 3 being high school graduate, 24 having an undergraduate degree and 59 being post graduates.

Investigation of a few key results showed that there exists an irony as $78.8 \%$ of respondents have not taken any class/course in financial literacy whereas $58.9 \%$ of the respondents are likely to take one if offered. Moreover, $44.4 \%$ of respondents do not own a credit card and only $14 \%$ of the respondents who own a credit card, pay the credit card bills themselves. $35.5 \%$ respondents do not bother to read all required information on financial documents before signing them.

Furthermore, it was seen that $71.2 \%$ respondents do not consider themselves as financially literate however $68.8 \%$ of respondents are still involved in household decisions related to finance. It was clearly visible that respondents lacked knowledge on topics such as inflation, credit score and insurance with $57.8 \%$ respondents, $43.3 \%$ respondents and $43.3 \%$ respondents being uninformed on them respectively. Another vital piece of information found was that even though $90 \%$ of the respondents own a bank account, 57.5\% respondents do not know the concept of compound interest.

A summary of responses is given in the table and charts below. All the responses are made available for preview in the Appendix II.

\section{Chart 1 - Gender of Survey Participants}

\section{Gender}

90 responses

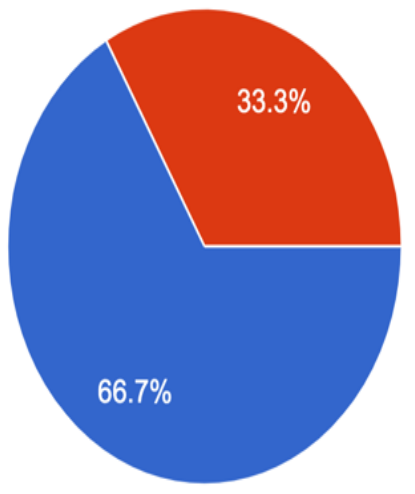

Female

Male

Other

Prefer not to say 


\section{Chart 2 - Age of Survey Participants}

State your age

90 responses

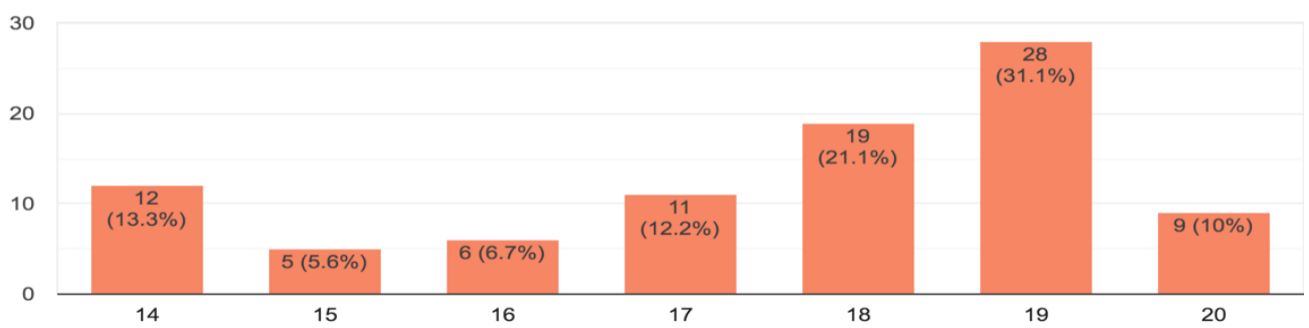

\section{Chart 3 - Parental Qualification of Survey Participants}

What is the qualification of your parents?

90 responses

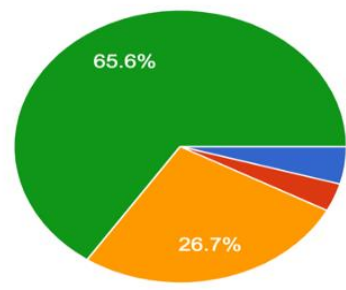

Table 1: Basic Knowledge of Finance

\begin{tabular}{|l|l|l|}
\hline Topics & \% of correct answers & \% of incorrect answers \\
\hline Insurance & 56.7 & 43.3 \\
\hline Credit Score & 56.7 & 43.3 \\
\hline Car Insurance & 80 & 20 \\
\hline Renting & 62.2 & 37.8 \\
\hline Inflation & 42.2 & 57.8 \\
\hline Compound Interest & 42.5 & 57.5 \\
\hline
\end{tabular}

Table 2: Financial Attitude

\begin{tabular}{|l|l|l|}
\hline Questions & Low (\% of respondents) & High (\% of respondents) \\
\hline Level of Financial literacy & 71.2 & 28.8 \\
\hline Finances discussed in the family & 50 & 50 \\
\hline Importance of keeping financial records & 26.7 & 73.3 \\
\hline Importance of saving/invest money & 14.4 & 85.6 \\
\hline Uncertainness about money spent & 93.3 & 6.7 \\
\hline Capability of handling my financial future & 50 & 50 \\
\hline $\begin{array}{l}\text { Importance of reading financial documents } \\
\text { before signing }\end{array}$ & 34.5 & 64.5 \\
\hline $\begin{array}{l}\text { Importance of thinking affordability before } \\
\text { buying }\end{array}$ & 25.6 & 74.4 \\
\hline $\begin{array}{l}\text { Spending money makes me more satisfied } \\
\text { than saving it }\end{array}$ & 76.6 & 23.4 \\
\hline
\end{tabular}




\subsection{Infographic}

Once the survey results were viewed and compiled, an infographic was created in order to make the data easily comprehendible and attractive. This infographic was created using templates from Canva. It can be viewed below -

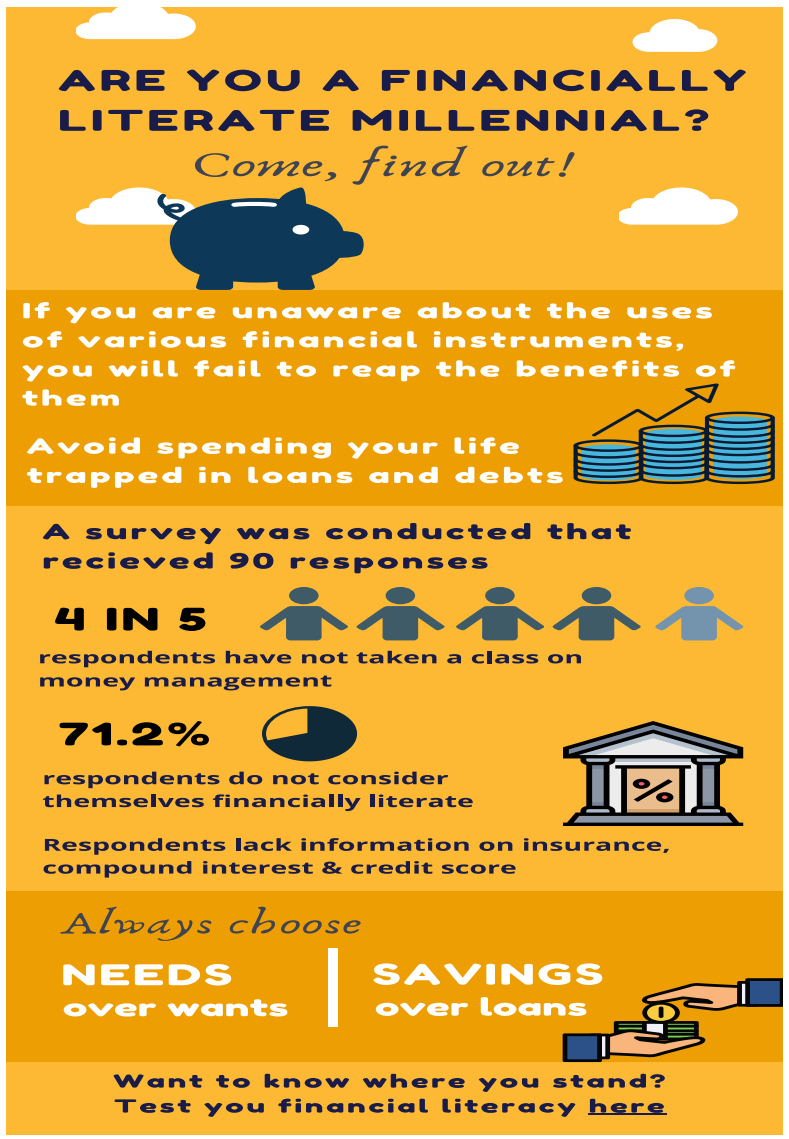

\section{Analysis \& Recommendations}

In this chapter, data collected from the financial literacy survey is analyzed and comparisons are made. It is concluded by including a few recommendations which can be implemented.

\subsection{Data Analysis}

The survey was taken by a diverse number of people, totaling to a 90 . Since the data was present for numerous respondents and covered a variety of topics, many conclusions could be made. The data analysis started with finding out the key results, followed by making comparisons between demographics such as age, gender and degrees of parental qualification.

The key results were quite interesting and gave us massive information about the current knowledge set of our target audience. A few of these are mentioned here. Only $24.4 \%$ respondents operate on a fixed daily/monthly budget while $64.4 \%$ of all respondents are not fully aware of their monthly allowance and expenses. $50 \%$ respondents discuss about finance with their parents. $50 \%$ are capable of handling their financial future. $37.8 \%$ respondents are not aware about the process of renting.

The data was divided into two age categories, one for 14-16-year-old students $(n=23)$, and the second for 19-20-year-old students $(n=37)$. The disparities between the two age groups are quite alarming. It was seen that while $64.86 \%$ of $19-20$ year-old respondents discuss about finance with their parents, only $21.74 \%$ of $14-16$-year-old respondents do so. 19-20-yearold respondents have taken more classes on financial literacy, are more aware of their daily/monthly budget and allowances than the younger age group. Yet, a higher percentage of 14-16-year-old respondents (52.17\%) think they are capable of handling their financial future than 19-20-year-old ones (45.95\%). Even though a majority of 19-20-year-old respondents think of it as important to keep financial records of bills/money spent, they are the more uncertain about where their money is spent as compared to the other age group. Most of the 14-16-year-old survey takers do not operate their own bank accounts whereas it is the opposite for 19-20-year-old participants who operate it by themselves. Due to their older age, 1920-year-old students would seem more informed and aware about financial literacy, however that it not the case. According 
to the survey, 14-16-year-old respondents have more knowledge about inflation, compound interest, credit score and insurance and 19-20-year-old respondents are more aware regarding only a few topics such as car insurance and renting.

Looking at the gender wise comparison, the survey was taken by 60 females and 30 males. From the overall responses, it is clear that males are more knowledgeable in financial literacy than females. About $23.3 \%$ males are involved in the financial decisions of the household as compared to $8.57 \%$ females. More males have taken classes on financial literacy, operate on a budget, and think they are financially literate. They discuss more about finances with their parents and are capable of handling their financial future. Males consider affordability more than females and know more about renting, inflation and compound interest. In contrast, females seem to be more informed on insurance and credit score. They pay more attention while signing financial documents and also while keeping records of their expenses.

The highest qualification of either of the respondent's parents was no high school degree $(n=4)$, high school graduate $(n=3)$, undergraduate $(n=24)$ and post graduate $(n=59)$. The group with undergraduate parents thinks they are the most financially literate $(41.7 \%)$, followed by postgraduate $(25.4 \%)$, then no high school degree $(25 \%)$ and finally high school graduates who did not consider themselves financially literate at all. The same order of knowledge as above was possessed on topics such as inflation, renting and insurance. Information was present in a descending order from post graduate to no high school degree on compound interest, even though most high school graduates own and operate their bank accounts. It was surprising to see that all respondents whose parents have a high school degree consider themselves capable of handling their financial future, followed by a $62.5 \%$ for undergraduate, $50 \%$ for no high school degree and only a $42.4 \%$ for post graduate parents.

\subsection{Recommendations}

The following are recommendations based on the data analysis, leading to a set of four recommendations.

- In a follow up study, the author should give more attention to getting close to an equal number of males and females to take the survey, who are spread equally across all age groups.

- A majority of the respondents are willing to take a class on financial literacy, and hence different boards across India should introduce it as a mandatory subject in all schools for students of all streams.

- Financial institutions should spread more awareness for opening and functioning of bank accounts, and method of investing in stock exchanges and other types of investments starting from a young age.

- Parents must discuss finance with their children on a regular basis and give them duties at a younger age itself so that they can learn the management of finance and work towards their financial independence.

\section{References}

[1] Organization for Economic Cooperation and Development. (2011). Measuring Financial Literacy: Questionnaire and Guidance Notes for Conducting an Internationally Comparable Survey of Financial Literacy: https://www.oecd.org/finance/financialeducation/49319977.pdf

[2] Monica Jasuja, (2017, February 26). Digital Financial Literacy - Key enabler for a less-cash India. https://www.finextra.com/blogposting/13750/digital-financial-literacy---key-enabler-for-a-less-cash-india

[3] Reserve Bank of India. (n.d). Financial Education https://www.rbi.org.in/financialeducation/Home.aspx

[4] National Institute of Securities Markets, A (2014) Pocket Money Programme:

[5] https://www.nism.ac.in/docs/Pocket\%20Money_A\%20Proposal\%20for\%20imparting\%20financial\%20education\%20to\%20school\%20 students_Website.pdf

[6] National Financial Educators Council. (n.d): https://www.financialeducatorscouncil.org/

[7] Reserve Bank of India. (2007). Financial Literacy for School Students

[8] https://www.rbi.org.in/financialeducation/SchoolChildren.aspx

[9] Reserve Bank of India, C (n.d). Financial Literacy Material - FAME Booklet https://www.rbi.org.in/FinancialEducation/fame.aspx

[10] Insurance Regulatory and Development Authority of India (n.d): Comic Strips http://www.policyholder.gov.in/Comic_Strips.aspx

[11] National Centre for Financial Education. (2015). Financial Awareness and Consumer Training (FACT) https://www.ncfe.org.in/program/fact

[12] National Centre for Financial Education. (2015). Money Smart School Program https://www.ncfe.org.in/program/mssp

[13] National Institute of Securities Markets, B (2014): NCFE - National Financial Literacy Assessment Test (NCFE-NFLAT) https://www.nism.ac.in/index.php/news1/535-ncfe-national-financial-literacy-assessment

[14] Kaushambi, (2017, June 15). 65 Percent Indians Lack Financial Literacy [Survey] https://trak.in/tags/business/2012/06/14/indiansfinancial-literacy-survey/

[15] Agarwalla, Barua, Jacob \& Varma, (2012, June). A Survey of Financial Literacy among Students, Young Employees and the Retired in India.

[16] https://faculty.iima.ac.in/ iffm/literacy/youngemployessandretired2012.pdf 
[17] Meera Santoshi, (2016, May 25). Financial Literacy in India: Statistics and Solutions. https://easybankingtips.com/financial-literacyindia-statistics/

[18] Jeremy Biberdorf, (2015, March 18). The Importance of Saving Your Money Starting at a Young Age. https://www.modestmoney.com/importance-saving-money-starting-young-age

[19] Jaimie Kemper, (2013, March 26). The importance of saving money at an early age. https://www.commonfloor.com/guide/theimportance-of-saving-money-at-an-early-age-24511.html

Appendix - I

Questionnaire circulated for the Financial Literacy Survey -

Category 1 : General Questions

Q1. Have you heard of the term financial literacy?

- Yes

- No

- Maybe

Q2. Are you involved in the financial decisions of your household?

- Yes

- No

- A little

Q3. Have you taken any class/course which has helped you in managing your money?

- Yes

- No

Q4. Would you consider taking such a class on financial literacy?

- Yes

- No

- Maybe

Q5. Do you operate on a daily/monthly budget?

- Yes

- No

- I try to

Q6. Are you aware of your monthly allowance and expenditure?

- Yes, I am fully aware

- No, I am not aware

- I am somewhat aware

Q7. Do you own a bank account?

- Yes

- No

- Yes, but I don't operate it

Q8. Who pays your credit card bills?

- I pay for them myself

- My parents/family pays them for me

- I don't know

- I don't own a credit card 


\section{Category 2: Rate on a scale of $1-10,1$ being the lowest and 10 being the highest}

Q9. How financially literate do you think you are

Define FL: a combination of awareness, knowledge, skill, attitude and behavior necessary to make sound financial decisions and ultimately achieve individual financial wellbeing.

Q10. How much do you discuss about finance with your parents?

Q11. How important is it to keep financial records/bills of where you spend your money?

Q12. How important is it to save/invest money every month?

Category 3: How much do you agree on a scale of 1-5? ( 1 = disagree, $5=$ agree $)$

Q13. I am uncertain about where my money is spent

Q14. I feel capable of handling my financial future

Q15. I read all financial documents before I sign

Q16. Before buying something, I think carefully if I can afford it

Q17. Spending my money makes me more satisfied than saving it.

\section{Category 4 : Financial Knowledge}

Q18. From the list below, choose the most important factors in determining the amount of money you earn.

- The skills you possess and who you know.

- Your GPA and ACT score.

- High school diploma and volunteer work.

- Both " $b$ " and "c"

\section{Q19. Which of the following financial products can help you lower your personal risk?}

- Insurance

- Mutual funds

- Retirement plans

- None of the above

\section{Q20. Why would I want to improve my credit score?}

Define credit score: It refers to a person's creditworthiness. Credit scoring is used by lenders to help decide on whether to extend or deny credit.

- To save money when purchasing a car with a loan

- To earn more interest on investments

- To help you get a job, because many employers check their prospective employees' credit Both "a" and "c"

\section{Q21. How do I decide how much coverage I need when selecting car insurance?}

- Do online research to find out the minimum coverage requirement for your state

- Ask salespeople from several different insurance companies

- Ask a friend or mentor with a high level of insurance expertise

- All of the above

Q22. How do you calculate the cost of renting a place to live in order to determine whether renting is an option for you? 
- Add the rent plus all the additional expenses of renting a place to determine whether the total aligns with your personal finance objectives.

- Estimate the exact rent costs and the cost of utilities.

- Identify the exact amount of rent that is owed each month to a landlord.

- List all the components of the rent amount you will pay to the landlord.

- Uncertain

Q23. If the current inflation rate is at $3 \% .$.

- Investments in securities (stock market, mutual funds) adjust to market conditions by $3 \%$.

- My net income needs to increase by 3\% to maintain my current lifestyle.

- My savings need to increase by 3\% to maintain my current lifestyle.

- Uncertain

Q24. Suppose you put ₹100 into a savings account with a guaranteed interest rate of $2 \%$ per year. how much would be in the account at the end of five years?

More than

- $\quad ₹ 110$

- Exactly ₹110

- Less than ₹110

- Or is it impossible to tell from the information given

- Don't know

Q25. State your age

\section{Q26. Gender}

- Male

- Female

- Other

- Don't want to mention

- Q27. What is the qualification of your parents?

- No high school degree

- High school graduate

- Undergraduate

- Post graduate

\section{Appendix II}

To view all of the individual responses of the Financial Literacy Survey, please click on the link provided below -

https://docs.google.com/spreadsheets/d/1zBa270nyTssdkb048gA80eEXP3CSdxVvQJKDDpECvFU/edit?usp=sharing 